\title{
Plano de Gestão da Conservação para edificações de valor cultural
}

Jorge Eduardo Lucena Tinoco ${ }^{1}$

Centro de Estudos Avançados da Conservação Integrada

\section{Resumo}

Esta comunicação trata do Plano de Gestão da Conservação como instrumento de planejamento que estabelece uma política de administração para o uso adequado dos espaços e dos componentes construtivos, bem como da manutenção periódica do imóvel. Aborda a carência atual, no âmbito técnico especializado da conservação do patrimônio construído, dos procedimentos para elaboração de um documento que concilie os processos políticos e administrativos de dotações orçamentárias e de captações financeiras versus as necessidades técnico-operacionais das obras e dos serviços. O artigo apresenta o case do Plano de Gestão da Conservação da Basílica da Penha, elaborado pelo Centro de Estudos Avançados da Conservação Integrada (CECl) no ano de 2006, como uma experiência exitosa para a garantia da integridade e autenticidade de um bem cultural construído.

Palavras-chave: Plano de gestão de conservação, plano diretor de conservação, conservação do patrimônio.

\section{Abstract}

This paper presents the Conservation Management Plan as a planning tool that establishes a policy administration for the proper use of spaces and building components, as well as periodic maintenance of the property. Shows the current shortage within technician built heritage conservation, procedures for the preparation of a document that reconciles the political processes and administrative budget allocations and fund raising needs versus technical-operational works and services. The article presents the case of the Conservation Management Plan of the Basilica da Penha, prepared by Centro de Estudos Avançados da Conservação Integrada (CECI) in 2006, as a successful experience to ensure the integrity and authenticity of a cultural building. 
Key words: Conservation management plan for cultural value buildings. Master plan for conservation. Conservation of heritage. Conservation Management Plan

\section{INTRODUÇÃO}

O Plano de Gestão da Conservação para edificações de valor cultural é um instrumento de planejamento que estabelece uma política de administração para o uso adequado dos espaços e dos componentes construtivos, bem como da manutenção periódica do imóvel. Tem como finalidade a garantia para a sociedade da integridade física do edifício e dos valores de significância do bem cultural que se quer preservar. Trata-se de uma ferramenta que se apresenta como um novo modelo de gestão a ser adotado pelo poder público e pela iniciativa privada na conservação do patrimônio cultural construído.

No Brasil de hoje, é patente que os métodos correntes e as técnicas de projetos de restauro privilegiam apenas a execução das obras, seguindo na contramão das condutas mais avançadas para a salvaguarda da herança cultural construída. Há uma lacuna no meio técnico especializado da conservação do patrimônio construído quanto aos procedimentos para elaboração de um planejamento integrado para a conciliação dos processos políticos e administrativos de dotações orçamentárias e de captações financeiras versus as necessidades técnico-operacionais das obras e dos serviços.

É comum constatar-se que os projetos de conservação são totalmente dissociados das ações periódicas e contínuas da gestão e da manutenção da edificação. $O$ planejamento mais avançado tem que extrapolar as questões básicas e cotidianas comuns às planilhas orçamentárias e aos cronogramas físico-financeiros dos projetos. Não fazer previsões ou estabelecer parâmetros e custos quanto à manutenção da edificação na qual se pretende empreender a conservação e o restauro é uma prática lesiva aos cofres públicos e à poupança privada. 
Desde a criação de programas governamentais sistematizados de preservação, a partir da década de 1970, até os primeiros anos deste novo século, as obras e os serviços em edificações de valor cultural, sob a proteção do poder público, valemse da expertise dos profissionais e dos métodos operacionais da construção civil na condução dos principais empreendimentos. O Curso de Gestão de Restauro do Centro de Estudos Avançados da Conservação Integrada $(\mathrm{CECl})^{2}$, através de viagens de estudo pelas principais cidades históricas do Nordeste e Sudeste do Brasil, tem verificado que as expectativas quanto à qualidade final das intervenções tomam de empréstimo parâmetros utilizados pelo mercado imobiliário, particularmente das áreas das construções habitacionais e comerciais, nem sempre adequadas aos materiais, técnicas e sistemas construtivos tradicionais. Dentre os vários materiais e procedimentos, aqueles que mais causam interferências nas edificações antigas são os relativos às inovações tecnológicas, particularmente de materiais sintéticos para impermeabilidade e estanqueidade das estruturas e revestimentos, conforto térmico, comunicações etc.

Dos projetos da primeira hora do Programa de Cidades Históricas $(\mathrm{PCH})^{3}$ aos atuais relativos aos eixos um e dois do Programa de Aceleração e Crescimento (PAC) das Cidades Históricas ${ }^{4}$, não há previsão de dotações orçamentárias (para o caso do ente público) ou de capacidade econômico-financeira (no caso de ente privado) para se manter adequadamente o uso da edificação, sequer num horizonte mínimo de 10 anos.

Ainda em nosso meio, parece que a antiga assertiva do artigo 9o da Carta de Veneza de 1964 de que a restauração é uma operação que deve ter caráter excepcional ainda não encontrou ressonância no âmbito do poder público, seja federal, estadual ou municipal, quiçá junto a alguns profissionais especialistas. A restauração deve ceder à conservação. A política de manutenção tem de ser estimulada, implementada e garantida. Urge, portanto, uma mudança de paradigma.

\section{PLANO DE GESTÃO DA CONSERVAÇÃO}

O Plano de Gestão da Conservação (PGC) ${ }^{5}$ é composto por um conjunto de documentos técnicos comprometidos com ações integradas de curto, médio e longo 
prazos para a realização de ações conservativas que não podem mais ser abordadas com a visão imediata da obra de restauro, que se encerra com as solenidades de aposição de placas pelos políticos ou de outras comemorações.

O PGC não se limitada às ações das obras em si. Os procedimentos relacionados no plano devem ir além da entrega das obras ou serviços, monitorando a gestão do uso, bem como o desgaste e a falência natural dos seus componentes construtivos. Neste sentido, destacam-se as recomendações e orientações sobre as ações periódicas de inspeção e manutenção, bem como as estimativas dos custos desses procedimentos. A elaboração do plano deve ser iniciada pari passu com a idealização dos projetos, ainda nas pranchetas dos profissionais ${ }^{6}$. Devem se respaldar em estudos e no conhecimento dos procedimentos necessários às rotinas de inspeção e manutenção periódicas dos materiais e técnicas construtivas a especificar. A antevisão das capacidades de carga, a vida útil dos materiais, as situações de riscos, necessariamente, têm de ser abordadas.

Apresenta-se a seguir as experiências do $\mathrm{CECl}$ na elaboração e implementação do plano para a Basílica de Nossa Senhora da Penha, localizada na cidade do Recife, em Pernambuco, no período de fevereiro de 2006 a dezembro de 2012.

\section{BASÍLICA DE NOSSA SENHORA DA PENHA}

O PGC da Basílica da Penha foi elaborado pelo CECI no ano de 2006, por demanda da Província de Nossa Senhora da Penha do Nordeste do Brasil (PRONEB). O plano foi executado em duas etapas, pelo fato de a edificação encontrar-se em estado iminente de sinistros por incêndio e por desabamento. A primeira etapa consignou a proposta básica de intervenção das obras e serviços de conservação e restauro; a segunda contemplou os procedimentos e as orientações para a gestão do acervo cultural construído dos Capuchinos e as medidas para as inspeções e manutenções periódicas dos componentes construtivos, bem como as estimativas dos custos com essas despesas. 


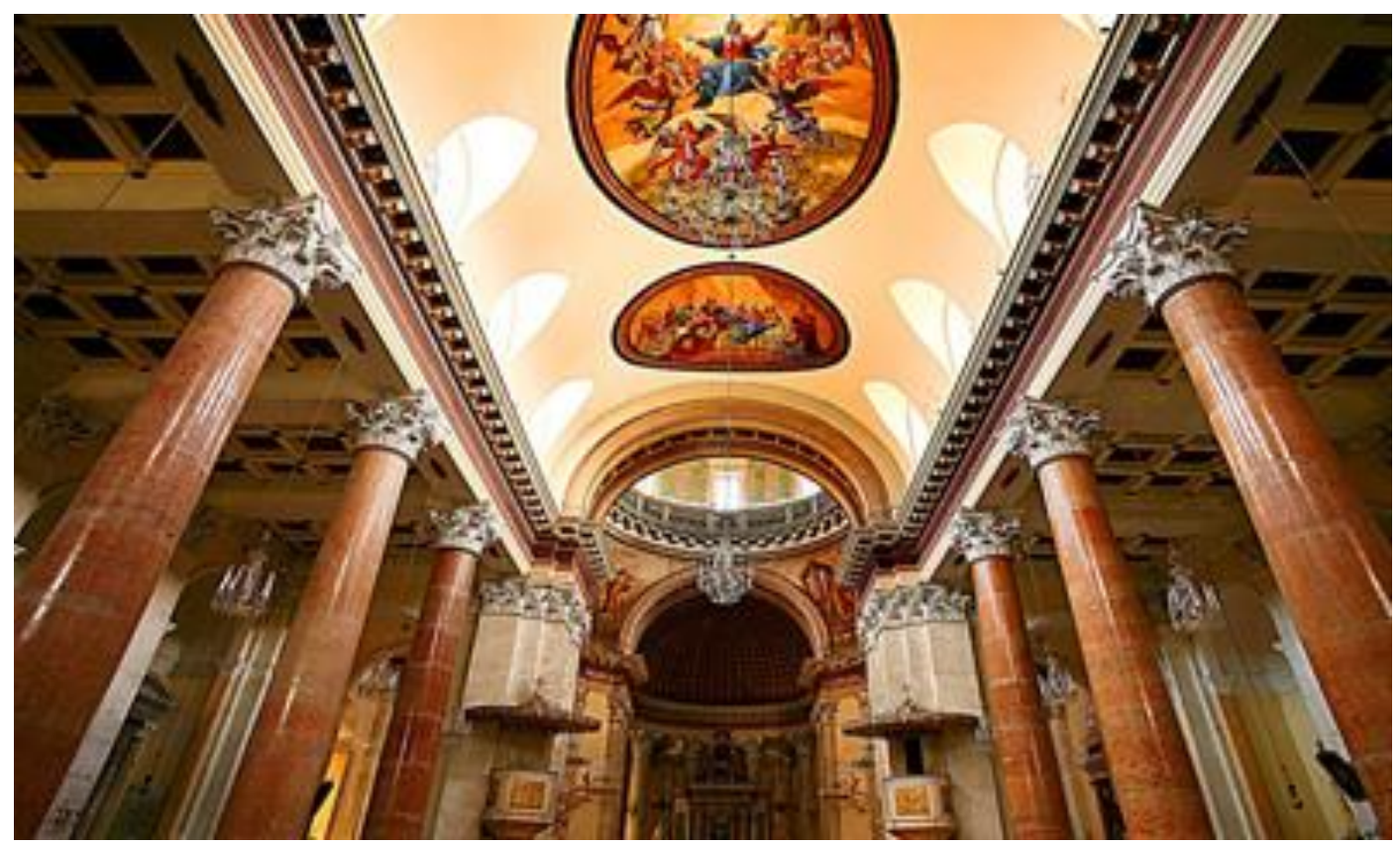

FIGURA 1 - Nave central da Basílica da Penha, ano 2008. Fotografia: Marta Lima.

O plano da Basílica consistiu na estruturação de ações de conservação integrada7, reunindo um conjunto de orientações técnicas direcionadas às intervenções físicas em nível de restauro da edificação. O plano tratou da identificação dos atributos tangíveis e intangíveis significativos da Basílica a serem preservados, sinalizou as patologias e os danos mais evidentes, definiu os principais atores responsáveis pela sua conservação e meios para sustentabilidade atual e futura da conservação do edifício. Teve por objetivo oferecer subsídios aos frades sobre as práticas protetivas de forma a instruir o pedido de tombamento em níveis estadual e federal, e de sugerir as alterações necessárias em seus estatutos para o favorecimento das tomadas de decisões e implementação das ações.

O plano teve como ponto de partida a Declaração de Significância da Basílica de Nossa Senhora da Penha, santa padroeira da indústria e do comércio da cidade do Recife. Essa declaração teve o intuito de evidenciar os valores essenciais materiais e imateriais atribuídos à edificação associados à sua estrutura de templo e às suas práticas religiosas e sociais, merecedoras de ações de salvaguarda e proteção, garantindo sua permanência no tempo. Assim, abriu-se a possibilidade de se instituir uma rotina de monitoramento da conservação capaz de assegurar a constante 
aferição e avaliação das mudanças pelo dia a dia do uso, estabelecendo estratégias para garantir a salvaguarda do bem cultural num horizonte de até 20 anos.

O plano da Basílica foi diferenciado dos outros dois elaborados pelo $\mathrm{CECI}$ para os Franciscanos de Olinda e Serinhaém, ${ }^{8}$ devido à urgência para se eliminar os riscos de incêndio e desabamentos. A primeira etapa foi elaborada em 45 dias. Um tempo recorde, considerando-se que a Basílica não possuía nenhum registro cadastral de plantas, por mais elementares que fossem. A segunda etapa foi realizada quando da captação dos recursos financeiros junto aos governos estadual e federal e à iniciativa privada ${ }^{9}$ para a execução das obras.

\section{Etapa I - Plano de Conservação Integrada}

O modelo elaborado e aplicado pelo $\mathrm{CECI}$ constou dos seguintes documentos:

Apresentação; Declaração de Significância; Localização; Propriedade; Vínculos Legais e Normas de Proteção; Antecedentes Históricos; Origens da Localização; Origem da Consagração da Construção Religiosa; Cronologia dos Processos Histórico-Construtivos; Significância Histórica; Características Físicas da Edificação; Registros Cadastrais (planta-baixa, fachadas, cobertas, usos, bens integrados); Patologias e Danos; Autenticidade e Integridade; Gestão da Propriedade (caráter social da comunidade, sustentabilidade, conservação atual); Planilha de Orçamento (estimativas de custos); Cronograma Físico-Financeiro; Referências Bibliográficas; Glossário; Ficha Técnica. (TINOCO, 2013, s.p.)

Dessa etapa destacam-se dois importantes documentos para a continuidade do plano na segunda etapa e para o novo processo de gestão adotado pelos Capuchinhos - a Declaração de Significância e o Mapa de Danos.

A Declaração de Significância da Basílica assim manifestou-se:

A Basílica de Nossa Senhora da Penha, da Ordem dos Frades Menores Capuchinhos, constitui um imponente edifício na paisagem urbana do Bairro de São José - fortemente marcada pela presença das torres sineiras altas e delgadas e da enorme cúpula do 
transcepto, símbolos de uma forte religiosidade - que norteou a configuração urbana do início da formação da cidade.

A volumetria da Basílica destaca-se no contexto pela sua monumentalidade e singularidade. Além da pertinência como elemento arquitetônico, o partido de planta em cruz, ao gosto românico, coroa a devoção religiosa cristã, tão forte na cidade do Recife.

A Basílica de Nossa Senhora da Penha merece uma emergencial ação de conservação por reunir os seguintes valores materiais e imateriais:

- Registra a monumentalidade da arte religiosa de estilo eclético, ${ }^{10}$ com influência do neoclassicismo da segunda metade o século XIX, no bairro histórico de São José, coração da cidade do Recife.

- Representa o vigor devocional e religioso marcante dos séculos passados e que perdura até os dias atuais sem perda de valor, recebendo semanalmente milhares de fiéis para as benções de São Felix e da Virgem ${ }^{11}$.

- Apresenta expressivos valores artístico e histórico refletidos em sua concepção de planta, volumetria e bens integrados, bem como a introdução de elemento abobadado em cúpula na sua coberta, materializando o poder religioso na paisagem urbana.

- É um dos mais representativos exemplares no Brasil das técnicas construtivas do primeiro período da arquitetura eclética ${ }^{12}$. Os trabalhos decorativos em estuque, particularmente nas técnicas do marmorino e escaiola, tanto no interior como no exterior, fazem-na única no Nordeste do Brasil.

O conjunto desses elementos representa a permanência dos valores simbólicos e documentais singulares, testemunho insubstituível da religião, da arte e da história, merecendo $o$ ato de preservação para conhecimento e usufruto das futuras gerações. (CECl, 2006, s.p.)

O Mapa de Danos foi elaborado a partir de fichas que permitiram a coleta em campo de dados técnicos da deterioração em todos os componentes construtivos. Esse documento serviu de base não só para a definição e dimensionamento dos serviços, mas, também, para a elaboração da metodologia de conservação da segunda etapa. 


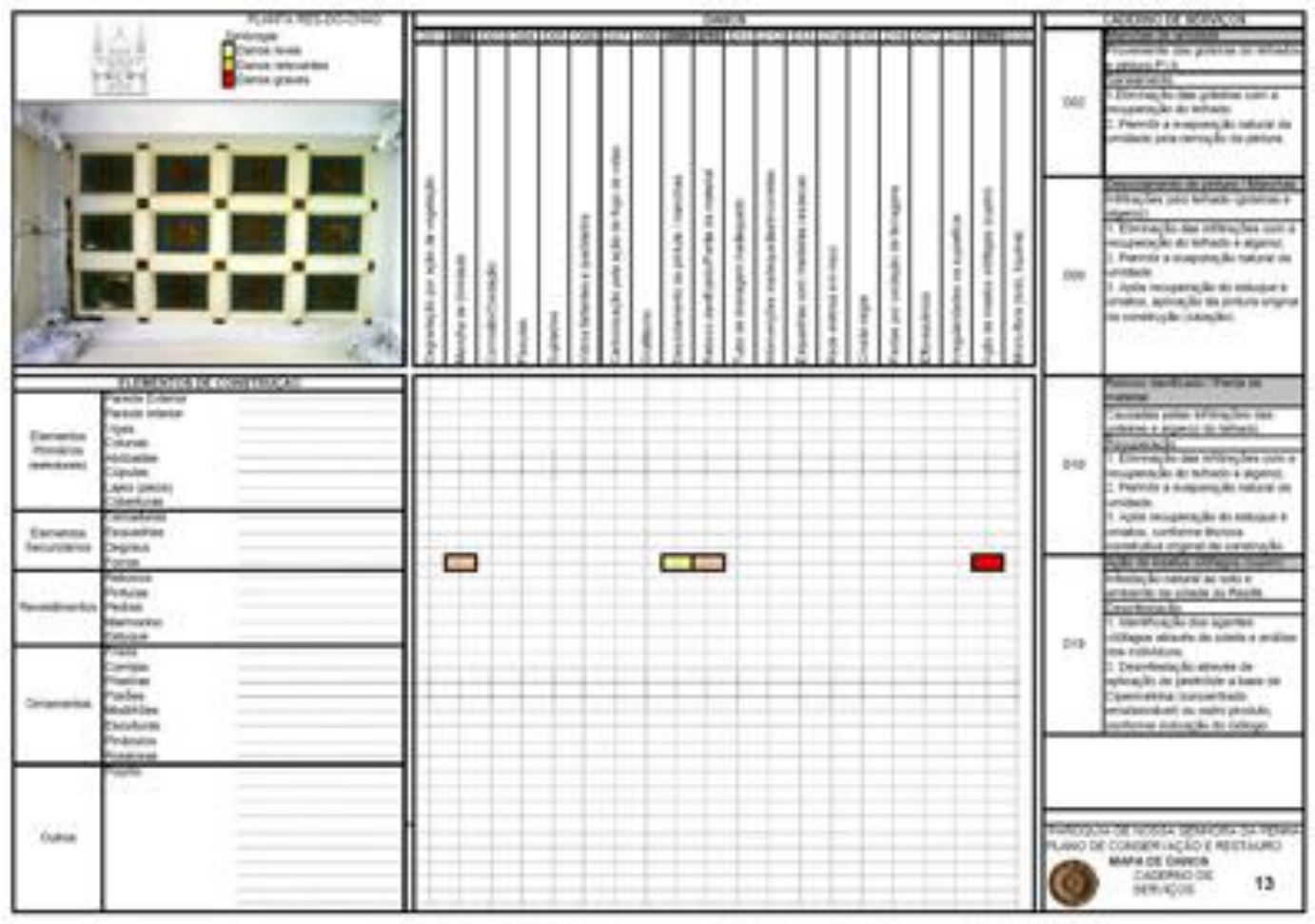

FIGURA 2 - Ficha de registro para elaboração do Mapa de Danos e do Caderno de Encargos. Desenho: Larissa Meneses, 2005.

O mapa foi configurado a partir da produção de 60 fichas contendo as principais patologias responsáveis pela degradação da Basílica. Os danos mais significativos estavam localizados nos telhados, devido às infiltrações generalizadas pelas ações inadequadas de alteração das técnicas e dos materiais; nas instalações elétricas remanescentes de $1918^{13}$ e pela proliferação de gambiarras e extensões de força e energia improvisadas; nos revestimentos internos e externos das paredes, degradados pela aplicação de tinta plástica à base de PVA látex.

\section{Etapa 2 - Plano de Gestão da Conservação}

A elaboração desse plano aprofundou as pesquisas e os levantamentos produzidos na primeira etapa. Foram revisados, ampliados e elaborados os seguintes documentos:

Todas as plantas cadastrais, através de levantamentos minuciosos, inclusive simulações em virtuais em 3D das técnicas dos sistemas construtivos dos telhados e imagens em VR360 tour ${ }^{14}$; o Inventário do Acervo dos Bens Arquitetônicos Integrados e Aplicados, bem como 
do acervo do mobiliário e das alfaias; os Projetos Complementares de Conservação e Restauro dos Elementos Artísticos com as respectivas Planilhas de Orçamento e Cronogramas ${ }^{15}$; os Manuais de Inspeção e de Manutenção periódicas; as alterações do Estatuto e do Regimento Interno da Proneb. (TINOCO, 2013, s.p.)

As alterações no estatuto da Proneb, os manuais de inspeção e manutenção periódicas e as fichas de identificação de danos (FID) são as peças em destaque nesta etapa. Sem estes documentos, não seriam viáveis ações planejadas de salvaguarda dos valores de significância da Basílica dentro dos preceitos da mínima intervenção e do respeito à autenticidade.

A principal alteração no Estatuto dos Capuchinhos foi a inserção do art. 51, segundo o qual "O Governo Provincial-Diretoria será assistido pela Comissão de Arte Sacra no âmbito da preservação do patrimônio cultural da Província" (PRONEB, 2012, p. 11). Essa comissão ficou responsável pela preservação dos bens patrimoniais de valor histórico e artístico reconhecidos pelo poder público através do instituto jurídico do tombamento, além daqueles classificados, tombados e registrados pela própria Comissão no Livro do Patrimônio Cultural da Província. No Nordeste do Brasil essa é a primeira notícia que se tem da introdução de um órgão no organograma jurídico de uma ordem religiosa para garantir a integridade e a autenticidade dos seus bens patrimoniais de valor histórico e artístico. Essa comissão já se encontra em plena atividade, tendo contratado um profissional com amplas habilidades nos principais ofícios tradicionais da construção, capacitado pelo $\mathrm{CECl}$ há mais de cinco anos, inclusive com participação nas obras de restauro da Basílica ${ }^{16}$.

Os manuais de inspeção e manutenção periódicas estabeleceram as ações de rotina para orientar os frades e funcionários da Basílica nas suas atividades como moradores e observadores dos espaços e dos componentes construtivos da edificação. Com um texto coloquial, fornece orientações que buscam sensibilizar essas pessoas de forma a criarem um olhar mais apurado, capaz de identificar pequenos sinais de degradação, possibilitando uma intervenção precoce e menos invasiva ao patrimônio ${ }^{17}$. 
As Fichas de Identificação de Danos (FID $)^{18}$ são documentos normalizados com registros e anotações gráficas e fotográficas sobre os danos existentes numa edificação. As FID contêm os registros principais para a produção do Manual de Manutenção de uma edificação de valor cultural porque cadastram desde as causas da degradação, quando da elaboração do Mapa de Danos, até as condutas propostas, os métodos e os materiais utilizados na realização das intervenções.

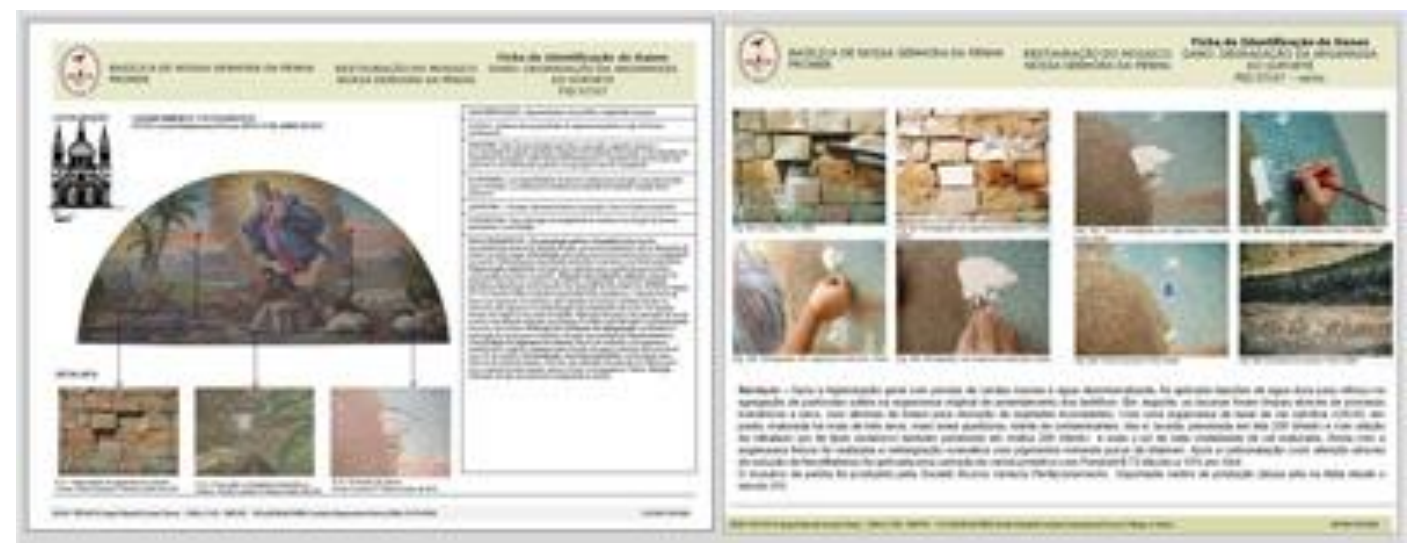

FIGURA 3 - Ficha de Identificação de Danos (FID), frente (registro dos danos) e verso (registro das intervenções) dos trabalhos de conservação do mosaico da Basílica. Manual de Manutenção da Basílica, Vol. 2, FID 07/07 e 07/07 - verso. Desenho: Luciana Nepomuceno, 2010.

São os documentos essenciais e indispensáveis para os procedimentos de intervenção de manutenções periódicas nos componentes construtivos de uma edificação. Sem os registros das origens, natureza, agentes e causas, além das anotações dos procedimentos e dos materiais utilizados nas intervenções, não é possível dar continuidade segura e econômica à conservação ${ }^{19}$.

\section{Considerações finais}

A modelagem e a aplicação do Plano de Gestão da Conservação é hoje uma ferramenta útil à administração das edificações de valor cultural. O plano pode garantir a eliminação de grandes intervenções de restauro num horizonte de até 20 anos, proporcionando reduções significativas dos custos, possibilitando a permanência dos valores de significância e de integridade da edificação. 
O custo para a produção do plano é relativamente baixo se comparado ao preço final de um projeto elaborado nos moldes atualmente exigidos pelo IPHAN ${ }^{20}$, pois pode ser considerado como um projeto complementar pela administração. Também os gastos com as inspeções e manutenções periódicas são reduzidos. Tomando-se por base a área de $1.200 \mathrm{~m}^{2} \mathrm{e}$ a ordem de grandeza dos componentes construtivos e dos elementos artísticos integrados e aplicados da Basílica da Penha, a paróquia tem um custo médio mensal de $R \$ 4.200,00$ com mão de obra, mais $R \$ 1.800,00$ com materiais. Isto representará no longo prazo, no horizonte de 20 anos previsto no plano, um total de aproximadamente $R \$ 1.440$ mil, que é apenas $10 \%$ do total a ser gasto com o restauro em andamento ${ }^{21}$. Evidentemente, alguns procedimentos de manutenção exigirão maiores investimentos quando da execução dos serviços previstos nas manutenções quinquenais e decenais, como a repintura das fachadas externas e a substituição da fiação da rede de energia elétrica, cujo horizonte de vida útil média é de 10 anos, etc.

O cenário brasileiro para a gestão da conservação de edificações de valor cultural deve ficar aberto às recomendações periódicas emanadas pelos organismos e reuniões técnicas internacionais e nacionais. Os trabalhos que vêm sendo desenvolvidos pelo $\mathrm{CECl}$ e outras instituições ajudam na ampliação desse conhecimento, pois também se fundamentam em estudos realizados em teses de mestrado e doutorado por seus associados, no âmbito da academia, bem como na prática, junto às entidades que aceitaram essa nova maneira de pensar e agir sobre seus edifícios históricos.

\section{Notas}

(1) Arquiteto, especialista, responsável técnico do CECl. e-mail: tinoco@ceci-br.org

(2) Curso de Gestão e Prática de Obras de Conservação e Restauro do Patrimônio Cultural - Gestão de Restauro, aplicado pelo Centro de Estudos Avançados da Conservação Integrada (CECI) desde o ano de 2003. Atualmente encontra-se na 13ª edição. Ver: <www.ceci.educacao.biz>.

(3) Programa da antiga Secretaria de Planejamento da Presidência da República (SEPLAN), que inicialmente foi denominado Programa de Reconstrução das Cidades Históricas do Nordeste. Ler: Proteção e revitalização do patrimônio cultural no Brasil: uma trajetória, publicado em 1980 pela Fundação Nacional Pró-Memória, do então Ministério de Educação e Cultura. 
(4) Sucessor do Programa Monumenta, o Programa de Aceleração do Crescimento das Cidades Históricas foi instituído em 2009. Disponível em: <http://www.pac.gov.br/noticia/b125fb32>. Acesso em: 30 jan. 2013.

(5) Também denominado Plano Diretor de Conservação.

(6) Pranchetas, no sentido metafórico, ou seja, nos desktops, notebooks e nas mesas de reuniões, pois a prancheta é uma mobília do passado em que se desenhavam os projetos.

(7) Para o caso do patrimônio cultural construído, este autor define conservação integrada com a conjugação de esforços técnicos, administrativos e políticos para a realização de operações de salvaguarda da edificação com vistas à garantia da sua integridade e dos seus valores de significância.

(8) Plano Diretor do Conjunto Franciscano de Olinda e Plano Estratégico para uso e ocupação do Convento Franciscano de Serinhaém. Disponível em: <http:/www.ceci-br.org/ceci/br/cooperacao/trabalhos/planodiretor.html>; e em: <http://www.ceci-br.org/ceci/br/noticias/276-plano-estrategico-do-convento-franciscano-deserinhaem.html>. Acessos em: 10 fev.2013

(9) Governo do Estado de Pernambuco, através da Fundação do Patrimônio Histórico e Artístico de Pernambuco (FUNDARPE); Governo Federal, pelo MinC/Pronac, através do Banco Nacional de Desenvolvimento Social e Econômico (BNDES) e da Oi Futuro; e doações de particulares feitas pelos devotos de São Félix.

(10) Quando da emissão dessa declaração, os estudos que demonstram ser a Basílica neoclássica, com inspiração paladiana em San Giorgio Maggiore de Veneza, ainda não haviam sido elaborados.

(11) Na primeira sexta-feira do ano a Benção de São Félix recebe mais de 60 mil fiéis. Essa quantidade é aferida pelo número de hóstias que são confeccionadas para distribuição na Eucaristia. Fonte: Paróquia de Nossa Senhora da Penha, jan. 2013

(12) No caso, arquitetura neoclássica. Vide nota 9 .

(13) Livro do Tombo da Ordem dos Frades Menores Capuchinhos da Penha. Recife, 1920. Fonte: Arquivo do Convento da Penha do Recife.

(14) São imagens obtidas com câmeras fotográficas profissionais e especiais, dotadas do recursos High Dynamic Range (HDR). Sobre tour virtual, veja: <http://www.vr360.com.br>. Acesso em: 13 fev.2013.

(15) No âmbito da Proneb, esses projetos são denominados Pronac II, e fazem parte dos atuais esforços para a captação dos recursos financeiros para conclusão do restauro da Basílica.

(16) O mestre Cícero Benício da Silva foi o profissional mais adequado, porque participou das obras de restauro da Basílica desde dezembro de 2007 até abril de 2012. Aliás, o procedimento de manter em prédios ou conjuntos habitacionais recém-construídos uma testemunha, ou memória viva das obras, é uma prática corriqueira das administradoras de condomínio. 
(17) Mesmo modelo aplicado no Plano do Conjunto Franciscano de Olinda. Ob. Cit. v. 3, p. 61. CECl, Olinda-PE, 2005.

(18) TINOCO, Jorge E. L. Mapa de danos: recomendações básicas. Olinda: CECI, 2009. (Textos para Discussão, v.43 Série 2: Gestão de Restauro) Disponível em: < http://www.ceci-br.org/ceci/br/publicacoes/textospara-discussao.html >. Acesso em: 20 fev. 2013.

(19) Por analogia, podem-se comparar as FID de uma edificação com as fichas de um dentista de família, que mantém ao longo do tempo o conhecimento e o controle sobre saúde dos dentes dos seus clientes.

(20) O manual que orienta a elaboração e a apresentação de projetos a serem submetidos ao Iphan não contempla a exigência dos manuais de rotinas de inspeção e manutenção periódicas. Disponível em: http://www.monumenta.gov.br/upload/Manual\%20de\%20elaboracao\%20de\%20projetos 1168630291.pdf>.

Acesso em: 19 fev. 2013.

(21) Valores de fevereiro de 2013. As despesas mensais são exclusivas das atividades previstas nas Rotinas de Inspeções e Manutenções. Fonte: Paróquia de Nossa Senhora da Penha, Recife-PE.

(22) Para acesso à relação atualizada de instrumentos utilizados, consulte a página Descrição Arquivística, 20102013. Disponível em: <http://www.arquiamigos.org.br/thesaurus.htm>.

\section{REFERÊNCIAS}

CENTRO DE ESTUdOS AVANÇADOS DA PRESERVAÇÃO INTEGRADA. Conservação da Basílica da Penha: proposta de tombamento. Olinda: CECl, 2006. Disponível em: < http://www.ceci-br.org/ceci/en/noticias/477tombamento-da-basilica-da-penha.html>. Acesso em: 19 nov. 2013.

FUNDAÇÃO NACIONAL PRÓ-MEMÓRIA. Proteção e revitalização do patrimônio cultural no Brasil: uma trajetória. Brasília: Ministério de Educação e Cultura, 1980.

ORDEM DOS FRADES MENORES CAPUCHINHOS DA PENHA. Livro do tombo. Recife, 1920.

PROVÍNCIA NOSSA SENHORA DA PENHA DO NORDESTE DO BRASIL. Estatuto. Recife, 2012.

TINOCO, Jorge E. L. Mapa de danos: recomendações básicas. Olinda: CECI, 2009. (Textos para discussão, v.43. Série 2: Gestão de restauro) Disponível em: <http://www.ceci-br.org/ceci/br/publicacoes/textos-paradiscussao.html >. Acesso em: 20 fev. 2013.

TINOCO, Jorge E. L. Planos de conservação: do ensino à prática, da academia aos canteiros de obra. Olinda: CECI, 2013. (Textos para discussão, v.55. Série 2: Gestão de restauro)

ZANCHETI, Silvio et al. Plano diretor do conjunto franciscano de Olinda. Olinda: $\mathrm{CECl}_{,=} 2005$. Disponível em: <http://www.ceci-br.org/ceci/br/cooperacao/trabalhos/plano-diretor.html>. Acesso em: 10 fev. 2013. 
ZANCHETI, Silvio et al. Plano estratégico para uso e ocupação do convento franciscano de Serinhaém. Olinda: CECl, 2007. Disponível em: <http://www.ceci-br.org/ceci/br/noticias/276-plano-estrategico-do-conventofranciscano-de-serinhaem.html>. Acesso em: 10 fev. 2013. 